This is the final peer-reviewed accepted manuscript of:

Cornelsen, L., Green, R., Turner, R., Dangour, A. D., Shankar, B., Mazzocchi, M., and Smith, R. D. (2015) What Happens to Patterns of Food Consumption when Food Prices Change? Evidence from A Systematic Review and Meta-Analysis of Food Price Elasticities Globally. Health Econ., 24: 1548- 1559. doi: 10.1002/hec.3107.

The final published version is available online at: https://doi.org/10.1002/hec.3107

Rights / License:

The terms and conditions for the reuse of this version of the manuscript are specified in the publishing policy. For all terms of use and more information see the publisher's website.

This item was downloaded from IRIS Università di Bologna (https://cris.unibo.it/)

When citing, please refer to the published version. 


\title{
What happens to patterns of food consumption when food prices change? Evidence from a systematic review and meta-analysis of food price elasticities globally.
}

Laura Cornelsen ${ }^{1}$, Rosemary Green ${ }^{1}$, Rachel Turner ${ }^{1}$, Alan D. Dangour ${ }^{1}$, Bhavani Shankar ${ }^{2}$, Mario Mazzocchi ${ }^{3}$, Richard D. Smith ${ }^{1}$

${ }^{1}$ London School of Hygiene and Tropical Medicine, London, UK

${ }^{2}$ School of Oriental and African Studies, University of London, London, UK

${ }^{2}$ Department of Statistical Sciences, University of Bologna, Bologna, Italy

Published on Health Economics, 24: 1548-1559 (2015) DOI: 10.1002/hec.3107

Pre-proof accepted version

Keywords: food consumption, food prices, cross-price elasticity, systematic review, meta-analysis

\begin{abstract}
Recent years have seen considerable interest in examining the impact of food prices on food consumption and subsequent health consequences. Fiscal policies targeting the relative price of unhealthy foods are frequently put forward as ways to address the obesity epidemic. Conversely, various food subsidy interventions are used in attempts to reduce levels of undernutrition. Information on price elasticities is essential for understanding how such changes in food prices affect food consumption. Not only it is crucial to know own-price elasticities but also cross-price elasticities, as food substitution patterns may have significant implications for policy recommendations. While own-price elasticities are common in analyses of the impact of food price changes on health, cross-price effects, even though generally acknowledged, are much less frequently included in analyses, especially in the public health literature. This article systematically reviews the global evidence on cross-price elasticities and provides combined estimates for seven food groups in low-, middle- and highincome countries alongside previously estimated own-price elasticities. Changes in food prices had the largest own-price effects in low-income countries. Cross-price effects were more varied and depending on country income level were found to be reinforcing, undermining or alleviating own-price effects.
\end{abstract}




\section{Background}

The price of food has become an increasing preoccupation amongst those concerned with nutrition and obesity. In low-income countries, where expenditure on foods can take up to $62 \%$ of income $(\mathrm{Gao}, 2012)$, the increasing real price of food since 2003 is likely to cause significant changes in diets and nutrient intake, with direct and indirect implications for health (FAO, 2012). Ruel et al. list various mechanisms in poor countries to cope with rising prices that contribute to issues related to both under- and over-nutrition, such as switching to low-quality, cheaper, staple foods; reduction in overall food intake; decrease in the consumption of nutrient rich non-staples; and an increase in the consumption of cheaper, high-calorie but low-nutrient 'street' food. (Ruel et al., 2010).

In middle- and high-income countries, where people spend on average much less on foods (6\%-30\% of their income) (Gao, 2012), a similar increase in food prices is likely to have a much smaller impact on consumption. However these countries are facing challenges from a growing prevalence of non-communicable diseases, for which diet is a significant risk factor, alongside physical inactivity, smoking, and alcohol use (WHO, 2010). As a response, governments are increasingly exploring the use of price as a mechanism to encourage people to consume less unhealthy foods and beverages and more healthy alternatives. Higher taxes on targeted foods or beverages are already in use in some countries (the US, Hungary, Finland, Norway, Ireland, France) and being debated in others (UK) (EPHA, 2012). Denmark introduced a 'fat tax' on products with saturated fat content above $2.3 \%$ in 2011 and although the tax was withdrawn, the preliminary evidence showed a reduction in the demand of the targeted nutrients by 10-20\% (Jensen and Smed, 2012).

Regardless of the source of food price increases, and the population affected, information on price elasticity is essential for understanding the extent to which changes in food price affect 
food consumption and ultimately health. In the literature analysing the impact of food prices on health the focus is typically on own-price elasticities in the context of rising obesity and non-communicable disease (see (Green et al. 2013, Eyles et al., 2012, Capacci et al., 2012, Andreyeva et al. 2010, Thow et al., 2010, Levy et al., 2011, Powell et al., 2009, Mytton et $a l ., 2012$ ) for review studies). Most of these reviews also point to a lack of knowledge and consideration of cross-price elasticities that explain substitution and complementarity (or income) effects. More recently studies have started to emerge in this area explicitly considering and discussing these effects, particularly from the USA, and the evidence does suggest that there are important policy implications (see for example Dharmasena and Capps 2012, Miao et al. 2012, Zhen et al. 2014). However, the findings are not always robust Finkelstein et al. (2013) for example found salty snacks and ice cream to be complements to sugar-sweetened beverages (SSB's) but Zhen et al. (2014) found substitution from SSB's to foods containing fat and salt. Miao et al.(2012) examined the effect of substitution within 25 food groups from high-fat to low-fat and high-sugar to low-sugar products and found that without accounting for substitution a tax on fats is more efficient than a tax on added sugar but if substitution is accounted for, the opposite holds. Also, studies usually consider substitution patterns within a limited set of foods or beverages rather than across the whole diet. Further, the evidence on cross-price effects is generally in the context of 'taxing foods or beverages' whereas these substitution patterns might also play an important role in the analysis of the impact of food price changes on under-nutrition.

To understand cross-price effects more fully this review synthesises the global, often heterogeneous, evidence on these effects across the whole diet. A systematic review of studies that have estimated food cross-price elasticities was conducted, and meta-regression was used to provide combined estimates across seven food groups for high-, middle- and low-income countries, while controlling for different study characteristics. The results are 
presented and discussed alongside own-price elasticities estimated from a similar systematic review and analysis conducted by the authors and available elsewhere (Green et al. 2013).

\section{Methods}

\subsection{Search strategy and inclusion criteria}

To retrieve studies presenting cross-price elasticities we searched for both scientific papers and grey literature using a pre-specified list of search terms (see Appendix 1) with an enddate of 28th of November 2012 in five relevant databases (ISI Web of Science, EconLit, Medline, AgEcon and Agricola) and in other online resources (Google, Google Scholar, Ideas REPEC, Eldis, websites of US Department of Agriculture, FAO, World Bank and IFPRI). The study protocol can be accessed from: http://www.lshtm.ac.uk/eph/dph/research/nutrition/research/agriculture/systematic_review_pr otocol_.pdf

Two authors independently conducted the literature search and identified relevant papers. Abstracts and full texts were screened for inclusion according to pre-specified criteria (see below) and all included studies were then checked by another author, and disagreements were resolved after discussion

Inclusion criteria:

We include full text studies with English abstracts employing nationally representative data collected after 1990 using cross-sectional, cohort, experimental or quasi-experimental design, and presenting uncompensated food price elasticities for disaggregated food groups, calculated using multiple equation methods and employing consumer prices of food items. 


\subsection{Data extraction}

Data were extracted into a database in MS Access recording information on the publication, data and methods used in the study, reported uncompensated price elasticities and their precision, by food items. The focus was on Marshallian (uncompensated) elasticities, both because these are most commonly reported in empirical studies, and are arguably most relevant for policy, especially when the aim is to allow for heterogeneity across income groups.

Individual food items were later aggregated into nine food groups: fruit and vegetables; meat; fish; eggs; dairy; cereals; fats and oils; sweets, confectionery and soft drinks (sweets); and other food (see Appendix 2). Simple average elasticities were calculated if the study presented elasticities for more than one group (e.g. different income groups or urban and rural). Data checking was done by another author for $20 \%$ of randomly selected studies and all differences were discussed and agreed upon.

\subsection{Statistical analysis}

In order to provide estimates of cross-price elasticities taking into account the different study characteristics, we employed a meta-regression model combining estimates from all the included studies. A standard meta-analysis approach was not possible as approximately half of the included studies did not report the required standard errors, confidence intervals or $p$ values. However, the benefit of predicting elasticities from a meta-regression analysis is that differences in methodological approaches or other study characteristics, which are often heterogeneous, are controlled for.

For the meta-regression analysis the dataset was divided into subsamples defined according to the food group of price change (e.g. all cross-price elasticities relating to the change in the 
price of meat are in one subsample). We excluded 'eggs' due to small numbers of observations $(n=187)$ and 'other food' $(n=420)$ as the majority of elasticities in this category were from a single study. Cross-price elasticities for food groups at a higher aggregation level than that used in this study (e.g. 'meat and dairy') were excluded. We also excluded crossprice elasticities that, due to aggregation, were within one food group (e.g. cross-price elasticity of pork to beef price and the other way around). We considered elasticities outside of the absolute value of three standard deviations of the mean, within the food group, to be outliers and removed these in each of the data subsets; this resulted in removal of $2.3 \%$ $(n=99)$ of the observations.

In the meta-regression model the dependent variable is the uncompensated cross-price elasticity and independent variables include dummy variables explaining the food group of consumption change, country income group (high, middle, low), type and frequency of the data used in the study (aggregate, cross-sectional household survey or longitudinal survey recorded monthly or more frequently, quarterly or annually) ${ }^{1}$, functional form of the demand model (almost ideal demand system (AIDS) or non-AIDS), and estimation methods (least squares (LS), seemingly unrelated regression (SUR), maximum likelihood (ML), other or missing). A further variable controlled for conditionality of the elasticities (unconditional, conditional on all food expenditure or conditional on food sub-group expenditure) as this can lead to systematic differences in elasticitiy estimates (Edgerton, 1997).

We also included dummy variables to control for whether studies addressed censoring in the data (coded as: data aggregated/averaged, two-step methods, other methods, not described or not applicable). Censoring in the data is a problem as the cause for zero-observations is

\footnotetext{
${ }^{1}$ Many studies use data recorded by households using hand-held scanners (e.g. Nielsen Homescan data in the USA). This data was recorded as longitudinal survey, cross-sectional or aggregate depending on how the data was manipulated in each study.
} 
usually unknown and, without corrections for it, price elasticities will be biased (Heien and Wessells, 1990).

Using unit prices (expenditure divided by quantity data) is a popular and simple solution to overcome the problem of missing price data in household expenditure surveys but these have been shown to be affected by measurement and quality bias $^{2}$ (Deaton, 1988). Thus we added a variable to control for which type of price data studies used and whether these biases had been addressed (coded as: quality adjusted unit prices, quality unadjusted unit prices, retail or consumer price index data, other (e.g. self-reported prices, shadow prices or a combination of different price data), or price data not described). Finally, we added a control for peerreviewed studies and for mean year of data from which the cross-price elasticities originated. Initially a two-level random intercept model was fitted for each subsample, with elasticity representing the first level, and study, the second level. However, according to a likelihood ratio test the two-level models did not offer any significant likelihood gains in comparison to ordinary one-level regression models which were consequently applied in the final models, estimated by ordinary least squares (OLS) with bootstrapped standard errors (50 replications). Because the number of explanatory variables is large, we included in the final models only those variables that are individually or jointly (when more than two categories) significant at least at the $10 \%$ level assessed by $\mathrm{t}$ - and $\mathrm{F}$-tests ${ }^{3}$, respectively.

We predicted cross-price elasticities by setting values of the covariates in the meta-regression model to their mean, with the exception of the dummy variables corresponding to food group of consumption change, country income level and mean year, which was set to 2008 . The

\footnotetext{
${ }^{2}$ Quality bias arise because goods purchased are generally at least to some extent aggregated (e.g. beef rather than specific cuts) and households at higher income level might be purchasing more expensive (higher quality) beef cuts compared to poorer households. Any price change is likely to affect both decisions on quantity and the quality of the foods

3 Except for food group and country income level variables, which were included to be able to predict the elasticities across these variables.
} 
means for the remaining variables were calculated from the whole dataset in order to reduce the impact of these study characteristics within each food group. Statistical analyses were performed in Stata 12.0 including 'xtmixed' commands (Statacorp., 2011).

\section{Results}

\subsection{Description of studies}

From the initial 2,094 records identified, N=78 studies were finally included (see Figure 1) presenting cross-price elasticities from 38 countries of which 13 are low-income $(\mathrm{N}=23), 11$ middle-income $(\mathrm{N}=18)$, and 14 high-income countries $(\mathrm{N}=37)$ (Table I). Altogether we extracted $n=4,162$ estimates of cross-price elasticities for seven food groups. Almost half of the cross-price elasticities looked at the changes in consumption when the price of fruits and vegetables $(n=983)$ or meat $(n=896)$ increases.

\section{Figure 1 here}

\section{Table I here}

More than half $(60 \%, n=2,515)$ of the estimates were from high-income countries, $19 \%$ from middle $(n=787)$ and $21 \%$ from low-income countries $(n=860)$. Only $30 \%(n=1,294)$ of the estimates were from peer-reviewed studies. Most estimates were from cross-sectional household or longitudinal survey data $(79 \%, \mathrm{n}=3,327$ and $17 \%, \mathrm{n}=677$, respectively). Annual and monthly frequency were most common $(53 \%, \mathrm{n}=2,231$ and $39 \%, \mathrm{n}=1,620)$.

We analysed the cross-price elasticities only by country income level as the number of studies estimating these by income groups within a country, but at national level, was too small $(\mathrm{N}=10)$ for a separate analysis. In the low-income country group, $49 \%(\mathrm{n}=425)$ of the 
estimates were from Asia (table 1), whereas the middle-income country group mostly consisted of estimates from Europe and South America (32\%, n=255 and 36\%, $\mathrm{n}=282$, respectively). High-income countries were dominated by data from Europe and North America (40\%, $\mathrm{n}=999$ and $51 \%, \mathrm{n}=1,283$, respectively).

More than half of the cross-price elasticities were estimated using an Almost Ideal Demand System (AIDS) or its variants $(78 \%, \mathrm{n}=3,250)$ and estimated with Seemingly Unrelated Regression (SUR) or its variant $(44 \%, \mathrm{n}=1,830)$ (see Appendix 4 for further details). Nearly half of the elasticities were from demand systems that are conditional on all food expenditure $(40 \%, \mathrm{n}=1,698)$. Censoring in the data was addressed by two-step procedures in $36 \%$ $(n=1,479)$ of the elasticities while for $19 \%(n=751)$ this was not described. More than half of the elasticities $(45 \%, n=1,865)$ were estimated using unit prices that were not adjusted to differences in quality.

\subsection{Meta-regression and predicted elasticities}

Predicted cross-price elasticities are shown by country income groups in Tables II, IV and V. As the focus of this study is on cross-price elasticities, we adopted own price-elasticity estimates from Green et al. (2013) which employs a similar methodology to predict food own-price elasticities but on a larger number of studies $(\mathrm{N}=136)$. All the own-price elasticities are significant at least at the 5\% level. Meta-regression results by data subsets and the values used for predictions are reported in Appendices 3 and 4, respectively.

\subsubsection{Low-income countries}

Food consumption was most sensitive to changes in prices in low-income countries, with the highest own-price elasticity estimates found for meat, fish, and dairy (Table II). Consumption of cereals and fats and oils was least sensitive to changes in prices, although all own-price 
elasticitiy estimates were still below -0.5 . However, as calories from cereals make up approximately half of all calories available in low-income countries (see Table III), an increase in cereal prices would have a bigger impact on diet relative to price increases in other foods (FAOSTAT, 2013).

\section{Table II here}

\section{Table III here}

We observed few cross-price effects that were significant at conventional statistical significance levels, which is partly due to a small number of observations in more than half of the cells, but not entirely surprising given that non-significant cross-price elasticities are found in many studies. The largest cross-price elasticities were found when the price of cereals increased. A $10 \%$ price increase was associated with a reduction in cereal consumption of $6.1 \%$ and with an increase in the consumption of fruit and vegetables, fish, dairy, fats and oils, and sweets of $0.65 \%, 0.92 \%, 1.17 \%, 0.71 \%$ and $0.74 \%$, respectively $(p<0.1)$. This added up to a $4.2 \%$ increase in consumption of these foods, but when translated into changes in calorie availability, the reduction in cereal consumption would only be replaced by a small amount of calories, as the share of other foods in the diet is modest (FAOSTAT, 2013).

An increase in the price of dairy of $10 \%$ was associated with a reduction in its consumption of $7.8 \%$ but with an increase in consumption of cereals of $0.68 \%(\mathrm{p}<0.01)$. Contrary to the above, the increased consumption of calories from cereals exceeds the reduction of calories from dairy, as the latter contributes very few daily calories (Table III).

An increase in the price of sweets by $10 \%$ was associated with a reduction in its consumption of $7.4 \%$ but also with an increase in the consumption of all other foods by 
approximately $1 \%$ each. As sweets provide a relatively small amount to daily calorie availability in low-income countries, the substitution towards more fruit and vegetables and cereals alone exceeds the reduction in calories from sweets (Table III).

\subsubsection{Middle-income countries}

The number of cross-price elasticities from middle-income countries was smaller in comparison to low- and high- income countries (Table III). Similarly to low-income countries only few cross-price elasticities were significant at conventional statistical significance levels. Animal sourced foods were most responsive to own-price changes while cereals and fats and oils were more staple foods with less price sensitive demand.

\section{Table III here}

Most statistically significant cross-price elasticities from middle-income countries were negative which indicates either complementarity or income effects. An increase in the price of fruits and vegetables by $10 \%$ was associated with a reduction in their consumption by $6.5 \%$. The same increase in the price of meat or fish led the quantities consumed of fats and oils to drop (by $0.74 \%$ and $1.26 \%$, respectively ( $<<0.05$ ), along with the consumption of fish and meat (by $7.2 \%$ and $7.3 \%$, respectively). This is likely to be a complementarity effect as fats and oils are used in the cooking process. However, the reduction in calories from fats and oils when the price of fish increased, was greater than the reduction in the calories from reduced demand for fish. This is due to fats and oils being more calorie-dense, and fish providing only a small share of daily calories (Table III).

An increase in the price of dairy products by $10 \%$ led to a reduction in dairy consumption of $7.2 \%$, and also a reduction in consumption of fruits and vegetables, meat and fish $(0.58 \%$, $0.45 \%$ and $0.59 \%$, respectively $(\mathrm{p}<0.1))$. Consumption of cereals fell by $5.5 \%$ if the price 
increased by $10 \%$, and this was also associated with an increase in dairy consumption $(0.6 \%$, $\mathrm{p}<0.05)$. An increase in the price of fats and oils by $10 \%$ was associated with a reduction in its consumption of 5.4\%, and a similar increase in the price of sweets was associated with a reduction in their consumption of $6.8 \%$. In these two food groups we did not find any statistically significant cross-price effects; partly due to the small number of observations.

\subsubsection{High-income countries}

The evidence from high-income countries was strongest, with more cross-price elasticities available than from low- and middle-income countries combined (Table IV). All own-price elasticities were, as expected, lower than in middle- or low- income countries.

\section{Table IV here}

As the number of observations was considerably larger, we observed more statistically significant cross-price elasticities, both positive and negative. An increase in the price of fruits and vegetables by $10 \%$ led to a reduction in their consumption of $5.3 \%$ and also to a reduction in consumption of fish, dairy and cereals of $0.15 \%, 0.3 \%$ and $0.2 \%$, respectively $(\mathrm{p}<0.1)$. A $10 \%$ increase in the price of dairy products, while reducing consumption of dairy products by $6 \%$, was also associated with a reduction in the quantities purchased of fruits and vegetables $(0.3 \%)$, fish $(0.32 \%)$ and cereals $(0.39 \%)(\mathrm{p}<0.05)$. A reduction in cereal consumption $(4.3 \%)$ due to a $10 \%$ price increase was, however, substituted with more consumption of fruits and vegetables $(0.48 \%)$, meat $(0.45 \%)$, fish $(0.75 \%)$, dairy $(1 \%)$ and sweets $(0.57 \%)(\mathrm{p}<0.1)$. These substitutions would replace approximately one third of the calories lost from cereal consumption (Table III).

An increase in the price of fats and oils by $10 \%$ was associated with a reduction in their consumption of $4.2 \%$, which indicates relatively inelastic demand. However, as for low- and 
middle-income countries, we did not detect any significant substitution patterns. The same increase in the price of sweets would lead to a greater reduction in their consumption $(5.6 \%)$, but an increase in consumption of all other foods, apart from fats and oils. These substitutions sum to a $3 \%$ increase in consumption of the other foods. When combined with data on calorie availability, the reduction in calories from fats and oils due to the price increase was greater than for sweets, as half of the calories reduced from sweets were substituted with cereals, dairy and fruits and vegetables.

\section{Discussion}

The aim of this review was to synthesise the global evidence on what happens to the consumption of different foods when food prices change, with a specific focus on cross-price effects. We have provided estimates for uncompensated food own- and cross-price elasticities for seven food groups for high-, middle- and low-income countries and interpreted the results in conjunction with FAO data on calorie availability from these foods which illustrate the significance of cross-price effects.

While the evidence on own-price elasticities is relatively good with 136 studies covering 162 countries, the 78 studies of cross-price elasticities included in our review only covered 38 different countries. Approximately half of the extracted cross-price elasticity estimates originated from high-income countries and were mainly for fruit and vegetables, and meat, indicating that the evidence base is poor, particularly in low- and middle-income countries.

The own-price effects were found to be significant at conventional statistical significance levels, and illustrated inelastic demand for broad food groups with low-income countries being most responsive to changes in food prices. However, even with relatively poor 
coverage of data on cross-price elasticities, the evidence shows that these effects are important as they can reinforce, undermine or alleviate the direct impact of a price increase.

While cross-price effects are estimated to be smaller than own-price effects, the impact on diet quality depends on the baseline consumption of the foods and nutrient profile of the foods. For example, in low-income countries when the price of cereals increased by $10 \%$, consumption dropped by $6.1 \%$ but the combined consumed quantities of fruits and vegetables, fish dairy, fats and oils and sweets increased by $4.2 \%$. However, as cereals provide nearly half of daily calories, the contribution of this substitution to overall calorie availability is relatively small, and an increase in the price of cereals in low-income countries would therefore be expected to have an impact on overall calorie intake. Conversely, lost calories from reduced dairy consumption due to price increases were fully substituted with calories from cereals.

An increase in the price of sweets in low- and high-income countries was associated with less consumption of sweets and more consumption of all other foods, except fats and oils. Thus, a tax on sugar, sweets and sweetened beverages could potentially induce, among others, more consumption of healthier alternatives such as fruit and vegetables, reinforcing the direct effect of the tax.

We combined price elasticities over studies and country income groups. The strength of our approach is that we provide elasticity estimates that control for country income level, data sources and year, models and estimation methods applied. Although combining elasticities from numerous countries with varying cultural backgrounds means combining different preferences and habits that affect the elasticity estimates, we do not consider this a specific problem for the review because any study, particularly those from large and culturally diverse countries, would face this problem. While we do not recommend using our estimates for 
individual country simulation studies, they do provide a useful input for multi-country scenarios.

Ideally this analysis should be repeated using low- and high-income populations within countries to address the regressive effect of food price increases. However, we found only ten studies that presented cross-price elasticities by income groups; too small for a combined analysis (see Appendix 5-6 for the references). Green et al. report greater differences within country by income groups for own-price elasticities compared to differences between high-, middle- and low-income countries and it is likely that this will also be the case with crossprice elasticities (Green et al., 2013). Therefore further research is needed that estimates consumer demand across populations with different attributes, including income, within a country.

A factor that was beyond the scope of this study, but is important in evaluating the impact of food prices on health, is how increasing food prices affect the consumption of non-foods (Smith, 2012). Regmi and Seale (2010) calculated the cross-price elasticities of broad expenditure groups with respect to an increase in the price of all foods (including alcohol and tobacco) for 114 countries using International Comparison Project Data from 1996, and found that income effects dominate in all countries, with the largest effects seen in lowincome countries: expenditure on medical care drops by $3.4 \%$ in low-income countries, $2.4 \%$ in middle-income countries and $1.9 \%$ in high-income countries following a $10 \%$ increase in food prices; spending on rent, fuel and power drops by $2.6 \%, 2.1 \%$ and $1.7 \%$, respectively in low-, middle- and high-income countries. These figures emphasise the wider impacts that food price increases may have on health which should be considered in policy analyses.

One of the limitations of our work is the use of aggregated food groups which may mask some of the substitution patterns within food groups (e.g. between beef and pork). Generally, 
studies either analyse relatively aggregated food groups, covering all foods, or focus on a particular subset allowing the estimation of price elasticities for detailed items. Therefore there is a trade-off in coverage of foods and the level of detail. While our approach may mask within food group substitutions, it has the advantage of providing an estimate of the impact across the diet. Furthermore, using broad food groups is more useful when taxes on an ingredient such as sugar, or subsidies on fruits and vegetables are analysed, since substitution within groups becomes less relevant when a tax or subsidy covers all foods within a group.

We analysed uncompensated (Marshallian) cross-price elasticities, thus allowing for both substitution and income effects. Because these effects act in opposite directions, the elasticity estimates are more likely to tend towards zero, which, together with the small number of observations, could explain the low significance of the elasticities estimated in this review. Alternatively, compensated (Hicksian) elasticities excluding the income effects could be analysed but these are much less commonly calculated (or presented). These would provide a better understanding of pure substitution effects in countries where incomes have grown together with prices or were compensated to losses due to price increases by some other means. However, if price increases exceed income growth, the use of Hicksian elasticities would become misleading under a policy perspective.

Another possible explanation for the relatively small values of the cross-price elasticities observed is the aggregation effect, since we have included only studies that use nationally representative data, combining the preferences and tastes of various consumer populations with different levels of accessibility and affordability. Averaging across these diverse groups of consumers leads to combining income, substitution and complementarity effects that, as mentioned, act in opposite directions and could therefore lead to small overall values. 
A further limitation is that elasticities are linear to changes in prices, which in reality may not be so as consumers are likely to react differently to large price increases compared to small increases. Therefore, simulations of the effect of a large tax on consumption are likely to be less accurate compared to a small tax which however has less impact on health outcomes. For example Mytton et al. (2012) suggest that a tax on unhealthy food and drinks should be at least $20 \%$ to have a significant effect on obesity and cardiovascular disease.

The review included only studies using data from 1990 onwards, and excluded studies that do not consider the demand for foods as a system with interdependencies. We have done so to ensure that we include only recent estimates found using statistical techniques which are consistent with the underlying economic theory. Excluding data before 1990 implies that we have not included numerous studies employing aggregated time series data. However, aggregated time series data have been shown to introduce a further aggregation error into the estimation of consumer demand (Denton and Mountain, 2011) and thus this criteriion ensures that the bias from the aggregation error is small.

We included both published and grey literature, as the latter forms a significant part of the evidence and often allows greater space for technical details and therefore better assessment of the study quality. Nonetheless, as many studies (particularly from low- and middle-income countries) do not report study methods rigorously it is not possible to assess the quality of all of these and any errors would carry over to the results of this review.

We assessed the quality of the included studies based on whether the description of data, methods and food groups is sufficient for replication of the study. We found that 26 studies $(\mathrm{n}=1,963)$ can be classified as "replicable" (see Appendix 5) but we do not provide a separate analysis because the number of countries these studies are from is much smaller compared to the overall analysis and we cannot be sure that the changes in the estimates are not due to 
differences in consumer behaviour in these countries rather than study quality. For example, $69 \%$ of the estimates from replicable studies are from the US compared to $51 \%$ in the whole sample for high-income countries (Table I). In middle-income countries 95\% of replicable estimates are from Lithuania or Turkey compared to $28 \%$ in the whole sample. Similarly in low-income countries the majority of replicable estimates (59\%) are from Tanzania and Uganda which provide $15 \%$ of the whole sample.

To conclude, there is a clear need for more robust information and understanding of how consumers change their consumption patterns across the diet when the prices of foods change in countries of different income levels. The meta-estimates of own-price elasticities indicate that changes in global food prices will have a greater effect in low-income countries and in poorer households within these countries (Green et. al.2013). Changes in the price of cereals will have the largest impact on calorie intake in low-income countries. The evidence on cross-price effects is more varied and less robust, but significant meta-estimates found even across relatively broad food groups suggest that these effects cannot be ignored. For example, fiscal policy in high-income countries increasing the price of sweets would lead to a reduction in their consumption but also substitution towards more fruit and vegetables hence there exists a reinforcing effect. Future studies should also consider differences in responsiveness to prices across income (and possibly other) groups within countries and be carried out using full demand systems that also consider non-food expenditures. There should be more rigorous reporting of the significance of the elasticities, which will allow consistent interpretation and combining estimates for similar populations for more robust results. 


\section{References}

Andreyeva, T, Long, MW, Brownell, KD. 2010. The impact of food prices on consumption: a systematic review of research on the price elasticity of demand for food. American Journal of Public Health, 100: 216-22.

Capacci, S, Mazzocchi, M, Shankar, B, Brambila-Macias, J, Verbeke, W, Perez-Cueto, F, Koziol-Kozakowska, A, Piorecka, B, Niedzwiedzka, B, D'addesa, D, Saba, A, Turrini, A, Aschemann-Witzel, J, Bech-Larsen, T, Strand, M, Smillie, L, Wills, J \& Traill, B. 2012. Policies to promote healthy eating in Europe: A structured review of policies and their effectiveness. Nutrition Reviews, 70: 188-200.

Deaton A. 1988. Quality, quantity and spatial variation of price. American Economic Review; 78: 418-30.

Denton, FT, Mountain, DC. 2011. Exploring the effects of aggregation error in the estimation of consumer demand elasticities. Economic Modelling, 28: 1747-1755.

Edgerton, DL. 1997. Weak separability and the estimation of elasticities in multistage demand system. American Journal of Agricultural Economics, 79: 62-79.

EPHA. 2012. Food taxation in Europe: Evolution of the legislation (update Ooctober 2012). Euopean Public Health Alliance. http://www.epha.org/a/4814 [December 2012].

Eyles, H, Ni Mhurcu, C, Nghiem, N \& Blakely, T. 2012. Food pricing strategies, population diets and non-communicable disease: A systematic review of simulation studies. PLOS Medicine, 9: 1-22.

FAO. 2012. Food Price Index. http://www.fao.org/worldfoodsituation/wfshome/foodpricesindex/en [December 2012]. 
FAOSTAT. 2013. Food supply. http://faostat3.fao.org [May 2013].

Finkelstein, EA, Zhen, C, Bilger, M, Nonnemaker, J, Farooqui, AM \& Todd, JE. 2013. Implications of a sugar-sweetened beverage (SSB) tax when substitutions to nonbeverage items are considered. Journal of Health Economics, 32: 219-239.

Gao, G. 2012. World food demand. American Journal of Agricultural Economics, 94: 25-51.

Green, R, Cornelsen, L, Dangour, AD, Turner, R, Shankar, B, Mazzocchi, M \& Smith, RD. 2013. The effect of rising food prices on food consumption: systematic review with meta-regression. $B M J$, 346: 13703 .

Heien D, Wessells CR. 1990. Demand systems estimation with microdata: a censored regression approach. Journal of Business \& Economics Statistics, 8: 365-71.

Jensen, JD \& Smed, S. 2012. The Danish tax on saturated fat - short-run effects on consumption and consumer prices of fats. Institute of Food and Resource Economics, University of Copenhagen.

Just, D. 2011. Behavioral economics and the food consumer. In: LUSK, J., ROOSEN, J. \& SHOGREN, J. (eds.) The economics of food consumption and policy. NY, US: Oxford University Press.

Levy, DT, Mabry, PL, Wang, YC, Gortmaker, S, Huang, TTK, Marsh, T, Moodie, M \& Swinburn, B. 2011. Simulation models of obesity: A review of the literature and implications for research and policy. Obesity Reviews, 12: 378-394.

Mazzocchi, M, Shankar, B \& Traill, B. 2012. The development of global diets since ICN 1992: Influences of agri-food sector trends and policies. FAO Commodity and trade policy research working paper No. 34 . 
Miao, Z, Beghin, JC \& Jensen, HH. 2012. Accounting for product substitution in the analysis of food taxes targeting obesity. Health Economcis, DOI: 10.1002/hec.2885.

Mytton, O, Clarke, D \& Rayner, M. 2012. Taxing unhealthy food and drinks to improve health. BMJ, 344:e2931.

Powell, LM, Zhao, Z \& Wang, Y. 2009. Food prices and fruit and vegetable consumption among young American adults. Health \& Place, 15: 1064-1070.

Regmi, A \& James L. Seale, J. 2010. Cross-price elasticities of demand across 114 countries. Economic Research Service, Technical Bulletin No. 1925. USDA.

Ruel, M, Garrett, J, Hawkes, C \& Cohen, M. 2010. The food, fuel, and financial crises affect the urban and rural poor disproportionately: A review of the evidence. The Journal of Nutrition, 140: 170S-176S.

Smith, R. 2012. Why a macroeconomic perspective is critical to the prevention of noncommunicable disease. Science, 337: 1501-1503.

Statacorp. 2011. Stata statistical software: Release 12. College Station, TX: StataCorp LP.

Thow, AM, Jan, S, Leeder, S \& Swinburn, B. 2010. Research. The effect of fiscal policy on diet, obesity and chronic disease: A systematic review. Bulletin of the World Health Organization, 88: 609-614.

WHO. 2010. Global status report on noncommunicable diseases. http://www.who.int/nmh/publications/ncd_report_full_en.pdf [December 2012].

Zhen, C, Finkelstein, EA, Nonnemaker, J, Karns, S, Todd, JE. 2014. Predicting the effects of sugar-sweetened beverage taxes on food and beverage demand in large demand system. American Journal of Agricultural Economics, 96:1-25. 
Table I Distribution of observations by country income group and region $(n=4,162)$

\begin{tabular}{|c|c|c|c|c|c|c|c|c|}
\hline $\begin{array}{l}\text { Low } \\
\text { income }\end{array}$ & $\mathrm{n}$ & $\%$ & Middle income & $\mathrm{n}$ & $\%$ & High income & $\mathrm{n}$ & $\%$ \\
\hline Africa & 185 & 21.5 & Africa & 139 & 17.7 & Australasia & 161 & 6.4 \\
\hline $\begin{array}{l}\text { Cote } \\
\text { d'Ivoire }\end{array}$ & 2 & 0.2 & South Africa & 139 & 17.7 & Australia & 161 & 6.4 \\
\hline Egypt & 38 & 4.4 & Asia & 42 & 5.3 & Asia & 72 & 2.9 \\
\hline Ghana & 21 & 2.4 & Turkey & 92 & 11.7 & Japan & 68 & 2.7 \\
\hline Tanzania & 82 & 9.5 & Saudi-Arabia & 4 & 0.5 & Taiwan & 4 & 0.2 \\
\hline Uganda & 42 & 4.9 & Europe & 255 & 32.4 & Europe & 999 & 39.7 \\
\hline Asia & 425 & 49.4 & Bulgaria & 11 & 1.4 & Denmark & 53 & 2.1 \\
\hline Bangladesh & 205 & 23.8 & Hungary & 10 & 1.3 & Finland & 19 & 0.8 \\
\hline Indonesia & 87 & 10.1 & Latvia & 20 & 2.5 & France & 447 & 17.8 \\
\hline Pakistan & 87 & 10.1 & Lithuania & 129 & 16.3 & Germany & 10 & 0.4 \\
\hline Philippines & 12 & 1.4 & Romania & 4 & 0.5 & Italy & 6 & 0.2 \\
\hline Vietnam & 34 & 4 & Slovenia & 28 & 3.6 & Norway & 11 & 0.4 \\
\hline S-America & 250 & 29.1 & N-America & 69 & 8.7 & Spain & 12 & 0.5 \\
\hline Bolivia & 70 & 8.1 & Mexico & 69 & 8.7 & Switzerland & 9 & 0.4 \\
\hline Ecuador & 14 & 1.6 & S-America & 282 & 35.8 & UK & 432 & 17.1 \\
\hline \multirow[t]{3}{*}{ Paraguay } & 166 & 19.2 & Brazil & 282 & 35.8 & N-America & 1283 & 51 \\
\hline & & & & & & Canada & 94 & 3.7 \\
\hline & & & & & & US & 1189 & 47.3 \\
\hline Obs. (n) & 860 & 21 & & 787 & 19 & & 2515 & 60 \\
\hline Studies (N) & 23 & 29 & & 18 & 23 & & 37 & 47 \\
\hline
\end{tabular}


Table II Predicted price elasticities for 2008 in low-income countries ( $\mathrm{n}=860 ; 23$ studies)

Price change

\begin{tabular}{r|lllllll} 
Consumption change & $\begin{array}{l}\text { Fruit \& } \\
\text { veg }\end{array}$ & Meat & Fish & Dairy & Cereals & $\begin{array}{l}\text { Fats \& } \\
\text { oils }\end{array}$ & Sweets \\
\hline Fruit \& veg & $\mathbf{- 0 . 7 2}$ & 0.005 & -0.014 & -0.001 & $0.065^{*}$ & -0.014 & $0.112^{* * *}$ \\
Meat & 0.02 & $\mathbf{- 0 . 7 8}$ & -0.008 & 0.011 & 0.062 & 0.016 & $0.101^{* * *}$ \\
Fish & 0.014 & 0.045 & $\mathbf{- 0 . 8 0}$ & -0.003 & $0.092^{* *}$ & 0.031 & $0.098^{* *}$ \\
Dairy & -0.001 & 0.003 & -0.02 & $\mathbf{- 0 . 7 8}$ & $0.117^{* * *}$ & 0.042 & $0.108^{* * *}$ \\
Cereals & 0.009 & 0.003 & -0.01 & $0.068^{* * *}$ & $\mathbf{- 0 . 6 1}$ & 0.006 & $0.1 * * *$ \\
Fats \& oils & 0.012 & -0.043 & -0.061 & 0.022 & $0.071^{*}$ & $\mathbf{- 0 . 6 0}$ & $0.094^{* *}$ \\
Sweets & 0.022 & 0.003 & -0.004 & 0.033 & $0.074 *$ & 0.022 & $\mathbf{- 0 . 7 4}$ \\
\hline $\mathrm{n}$ & 206 & 185 & 71 & 70 & 188 & 80 & 60 \\
\hline
\end{tabular}

Note: predictions based on a multiple regression model. Values of all covariates in the model are set to the mean of the total sample $(n=4,162)$ with the exception of the dummy variables corresponding to food groups and of mean year of data which is set to 2008. Highlighted cells outside the diagonal have less than 20 observations per cell; * statistically significant at $10 \%$ level, ** 5\%,***1\%, own-price elasticities on the diagonal are from Green et al. 2013 and all are significant at least $5 \%$ level. Sweets category includes sweets, confectionary and sweetened beverages. 
Table III. Average availability of calories (kcal) per capita per day in low-, middle- and high-income countries.

\begin{tabular}{|c|c|c|c|}
\hline \multirow[b]{2}{*}{ Food group } & \multicolumn{3}{|c|}{ Average calorie availability (kcal/per capita/day) } \\
\hline & $\begin{array}{c}\text { Low-income } \\
\text { countries }\end{array}$ & $\begin{array}{l}\text { Middle-income } \\
\text { countries }\end{array}$ & $\begin{array}{l}\text { High-income } \\
\text { countries }\end{array}$ \\
\hline Fruit \& veg & $535(22 \%)$ & $343(11 \%)$ & $330(11 \%)$ \\
\hline Meat & $152(6 \%)$ & $303(10 \%)$ & $419(14 \%)$ \\
\hline Fish & $31(1 \%)$ & $26(1 \%)$ & $64(2 \%)$ \\
\hline Milk & $74(3 \%)$ & $250(8 \%)$ & $334(11 \%)$ \\
\hline Cereals & $1210(50 \%)$ & $1241(42 \%)$ & $883(29 \%)$ \\
\hline Fats \& oils & $244(10 \%)$ & $484(16 \%)$ & $648(21 \%)$ \\
\hline Sweets & $173(7 \%)$ & $340(11 \%)$ & $404(13 \%)$ \\
\hline Total & $2419(100 \%)$ & $2987(100 \%)$ & $3082(100 \%)$ \\
\hline
\end{tabular}

Notes: Each country income group includes the same countries for which cross-price elasticities were retrieved. Source: (FAOSTAT, 2013) 
Table IV Predicted price elasticities for 2008 in middle-income countries ( $\mathrm{n}=787 ; 18$ studies)

\begin{tabular}{|c|c|c|c|c|c|c|c|}
\hline \multirow[b]{2}{*}{$\begin{array}{r}\text { Consumption } \\
\text { change }\end{array}$} & \multicolumn{7}{|c|}{ Price change } \\
\hline & $\begin{array}{l}\text { Fruit \& } \\
\text { veg }\end{array}$ & Meat & Fish & Dairy & Cereals & $\begin{array}{l}\text { Fats \& } \\
\text { oils }\end{array}$ & Sweets \\
\hline Fruit \& veg & -0.65 & -0.026 & $\begin{array}{l}- \\
0.079 * *\end{array}$ & $-0.058 * *$ & 0.007 & -0.039 & 0.034 \\
\hline Meat & 0.001 & -0.72 & $-0.073 * *$ & $-0.045^{*}$ & 0.005 & -0.01 & 0.024 \\
\hline Fish & -0.004 & 0.014 & -0.73 & $-0.059 * *$ & 0.035 & 0.005 & 0.021 \\
\hline Dairy & -0.02 & -0.028 & $-\overline{0.085 * *}$ & -0.72 & $0.06 * *$ & 0.016 & 0.031 \\
\hline Cereals & -0.01 & -0.028 & $-\overline{0.076 * *}$ & 0.012 & -0.55 & -0.02 & 0.023 \\
\hline Fats \& oils & -0.006 & $-0.074 * *$ & $-\overline{0.126 * *}$ & -0.035 & 0.014 & -0.54 & 0.017 \\
\hline Sweets & 0.003 & -0.028 & -0.069 & -0.024 & 0.017 & -0.003 & -0.68 \\
\hline $\mathrm{n}$ & 147 & 186 & 56 & 121 & 150 & 62 & 65 \\
\hline
\end{tabular}

Note: predictions based on a multiple regression model. Values of all covariates in the model are set to the mean of the total sample $(n=4,162)$ with the exception of the dummy variables corresponding to food groups and of mean year of data which is set to 2008. Highlighted cells outside the diagonal have less than 20 observations per cell; * statistically significant at $10 \%$ level, ** 5\%,***1\%, own-price elasticities on the diagonal are from Green et al. 2013 and all are significant at least $5 \%$ level. Sweets category includes sweets, confectionary and sweetened beverages. 
Table V Predicted price elasticities for 2008 in high-income countries ( $\mathrm{n}=2,515,37$ studies)

\begin{tabular}{r|lllllll}
\multicolumn{1}{l|}{$\begin{array}{l}\text { Consumption } \\
\text { change }\end{array}$} & $\begin{array}{l}\text { Fruit \& } \\
\text { veg }\end{array}$ & Meat & Fish & Dairy & Cereals & $\begin{array}{l}\text { Fats \& } \\
\text { oils }\end{array}$ & Sweets \\
\hline Fruit \& veg & $\mathbf{- 0 . 5 3}$ & 0.002 & 0.010 & $-0.030^{* * *}$ & $0.048^{*}$ & -0.033 & $0.060^{* *}$ \\
Meat & -0.009 & $\mathbf{- 0 . 6 0}$ & 0.016 & -0.018 & $0.045^{*}$ & -0.003 & $0.049^{* *}$ \\
Fish & $-0.015^{*}$ & $0.042^{*}$ & $\mathbf{- 0 . 6 1}$ & $-0.032^{* *}$ & $0.075^{*}$ & 0.012 & 0.046 \\
Dairy & $-0.03^{* *}$ & 0.001 & 0.004 & $\mathbf{- 0 . 6 0}$ & $0.100^{* *}$ & 0.023 & $0.057^{* *}$ \\
Cereals & $-0.02^{* *}$ & 0.000 & 0.013 & $0.039^{* *}$ & $\mathbf{- 0 . 4 3}$ & -0.013 & $0.048^{* *}$ \\
Fats \& oils & -0.017 & -0.046 & -0.037 & -0.007 & 0.054 & $\mathbf{- 0 . 4 2}$ & 0.043 \\
Sweets & -0.007 & 0.000 & 0.020 & 0.004 & $0.057^{* *}$ & 0.003 & $\mathbf{- 0 . 5 6}$ \\
\hline $\mathrm{n}$ & 630 & 525 & 260 & 366 & 332 & 123 & 279 \\
\hline
\end{tabular}

Note: predictions based on a multiple regression model. Values of all covariates in the model are set to the mean of the total sample $(n=4,162)$ with the exception of the dummy variables corresponding to food groups and of mean year of data which is set to 2008. Highlighted cells outside the diagonal have less than 20 observations per cell; * statistically significant at $10 \%$ level, $* * 5 \%, * * * 1 \%$, own-price elasticities on the diagonal are from Green et al. 2013 and all are significant at least $5 \%$ level. Sweets category includes sweets, confectionary and sweetened beverages. 
Figure 1 Flow chart of the search for studies

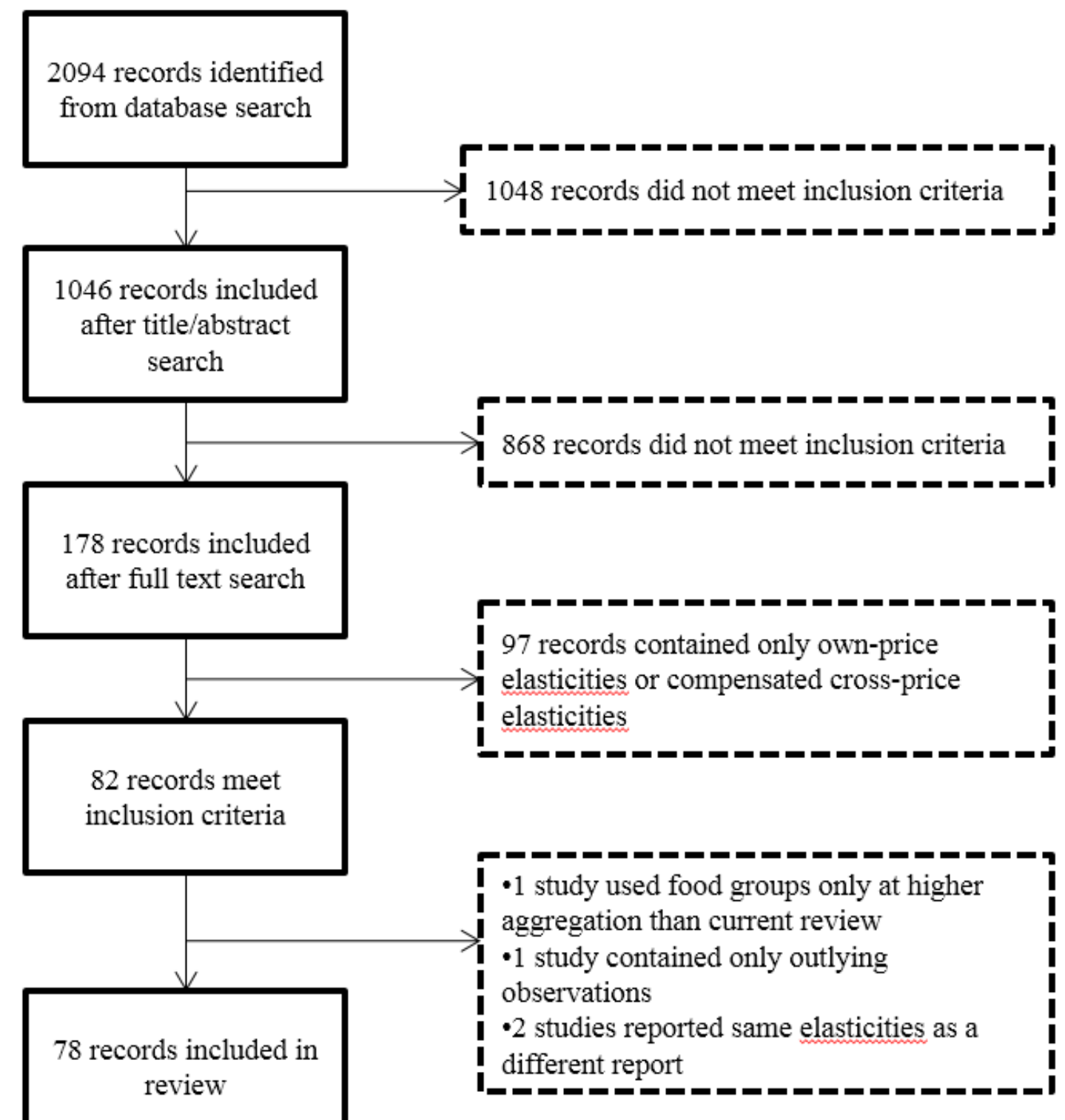

